\title{
Global Carbon di Oxide Emissions in Hamilton Filter Model
}

\author{
Dr. Debesh Bhowmik
}

Former Principal, Govt. of West Bengal, India, Honorary Research Prof. Lincoln University College, Malaysia

\begin{abstract}
The paper examined the cyclical trends, seasonal variation and seasonal adjustment of global $\mathrm{CO}_{2}$ emission from 1970 to 2018 through the application of Hamilton regression filter model. ARIMA (4,0,0) forecasting model for 2030 has been added with the Hamilton filter model and observed that the new model is stable, stationary and significant in which volatility is being minimised and the heteroscedasticity problem is totally disappeared.
\end{abstract}

Keywords- $-\mathrm{CO}_{2}$ emission, Hamilton filter, seasonal adjustment, cyclical trend, ARIMA forecasting.

JEL Classification codes-C13,C22,C50,O13,O40,Q54

\section{INTRODUCTION}

A series contains both the cyclical and seasonal behaviours. A seasonal behaviour is very strictly regular, meaning there is a precise amount of time between the peaks and troughs of the data. Cyclical behaviour on the other hand can drift over time because the time between periods isn't precise. A series with strong seasonality will show clear peaks in the partial auto-correlation function as well as the autocorrelation function, whereas a cyclical series will only have the strong peaks in the auto-correlation function. Patterns of peaks and troughs occur in both cyclical and seasonal analysis wherein seasonal trends the period between successive peaks (or troughs) is constant. But in cyclical trends the distance between successive peaks is irregular.

The decomposition of macroeconomic time series with trend and cyclical components is crucial to many macroeconomic concepts such as potential output, natural interest rate, share prices and inflation rate and so on. Econometric analysis requires filtering techniques which cater data sequences having short and strong trends. Filter can be used to decompose a time series into trend, seasonal and irregular components.

H.P.Filter (1997) has been used as a low pass smoothing filter in a numerous macroeconomic investigation setting smoothing parameter to certain arbitrary conventional values. It can decompose trend and cycles of the time series data to produce new time series such as potential GDP and output gap that are useful in macroeconomic discussion and in some recent public debate. It also used ARMA forecasting technique that deliver the required forecasted values that are needed in H.P. algorithm. The cyclical component obtained by H.P.Filter is unpredictable which indicates that we cannot do any investigation into the cyclical component because they are independent.

Many business cycles analysis, volatility of stock price indices and unemployment trends and cyclical patterns have been being studied through Baxter and King (1999) and Christiano and Fitzgerald (2003) models of decomposition of trends and cycles through filter till now.

Therefore, the author endeavours to examine the patterns of trends and seasonal and cyclical fluctuations of global $\mathrm{CO}_{2}$ emission during 1970-2018 by applying the methodology of Hamilton Filter model(2018).The paper also finds the projected rise of global $\mathrm{CO}_{2}$ emission in 2050 and examined the forecasting $\operatorname{ARIMA}(\mathrm{p}, \mathrm{d}, \mathrm{q})$ model incorporating in the Hamilton regression filter model up to 2030.

\section{SOME IMPORTANT STUDIES}

Bhowmik(2018) studied that global $\mathrm{CO}_{2}$ emission has been rising at the rate of $2.19 \%$ per year and global per capita $\mathrm{CO}_{2}$ emission has been catapulting at the rate of $0.58 \%$ per annum during 1960-2015.Global $\mathrm{CO}_{2}$ emission contains four upward structural breaks in 1968,1976,1988 and 2004 and per capita emission has two upward structural breaks in 1969 and 2004 respectively. World $\mathrm{CO}_{2}$ emission is positively related with global GDP and GDP per capita significantly during the specified period.There is no cointegration between world GDP and world $\mathrm{CO}_{2}$ emission during 1960-2015. 
Hamilton filter (2018) claims that H.P.Filter (1997) creates spurious dynamic relation, fails to eliminate spurious predictability,produces values for the smoothing parameter vastly at odds with common practice. It is not also a sensible approach for a random walk. Therefore, author uses regression variable at date $t+h$ on the four most recent values as of date $\mathrm{t}$ which is a better alternative to detrend and to extract cyclical components. Hamilton also assumes random walk, then cyclical component is estimated as $\mathrm{y}_{\mathrm{t}+\mathrm{h}}-$ $\mathrm{y}_{\mathrm{t}}$ which is predictable and perform much better than the H.P.Filter model.

Ciais et al.(2018) examined that since the beginning of the Industrial Era, fossil fuel extraction from geological reservoirs, and their combustion, has resulted in the transfer of significant amount of fossil carbon from the slow domain into the fast domain, thus causing an unprecedented, major human-induced perturbation in the carbon cycle during 2000-2009 which was observed a major change over preindustrial period. Emission of carbon from fossil fuel reserves, and additionally from land use change is now rapidly increasing atmospheric $\mathrm{CO}_{2}$ content.

Schuler (2018) applied Hamilton filter in the credit to GDP gap in USA taking data of GDP from Fred during 1947Q12017Q1 and data of credit GDP ratio from BIS during 1952Q1-2016Q4 which produced more robust cycle estimates than H.P. filter.

Bhowmik(2020) examined the growth rate of GDP in India during 2011Q4 -2019Q4 using quarterly data in explaining the trend,seasonal patterns and cycles in context of Hamilton regression filter model.The paper concludes that the TRAMO/SEATS of Hamilton filter produce clear seasonal variation showing $\mathrm{v}$ shaped volatility and cycles confirmed two peaks. ACF and PACF of Hamilton residual series verified the nature of seasonality. Residuals suffer from heteroscedasticity. $\operatorname{ARIMA}(1,0,0)$ process of Hamilton filter for forecasting 2030 converges to stable and stationary processes.

Even,Hodrick(2020) applied ARIMA model in Hamilton regression filter in decomposing cyclical components of US GDP during 1947Q1-2019Q1 using simulation technique and found that coefficient of $\mathrm{AR}(1)$ is greater than one and coefficients of $\mathrm{AR}(2)$ and $\mathrm{MA}(1)$ and $\mathrm{MA}(2)$ are less than one and the estimated equation is significant.

Oliver and Peter(2020) stated that global $\mathrm{Co}_{2}$ emission has increased by $1.6 \%$ per year during 1970-2003 which accelerated to $3.2 \%$ per year during 2003-2011 using the data set of EDGAR V4.2FT2010.
EDGAR(2020) stated that 2015 was the hottest year among the $16^{\text {th }}$ warmest year during $1998-2015$ but there was a structural break since annual growth rate of $\mathrm{Co}_{2}$ from 20122015 decreased especially in China, USA, EU, Canada and there was increased decoupling of $\mathrm{CO}_{2}$ emission and GDP.

Lindsey(2020) reported that during 1750-2019,the atmospheric concentration of $\mathrm{CO}_{2}$ in ppm has been steadily increasing but the $\mathrm{CO}_{2}$ emission has been catapulting along with small cycles.Author mentioned that $\mathrm{CO}_{2}$ concentration was never exceeded over $300 \mathrm{ppm}$ until preindustrial revolution, but in 1958 it reached to 315 and in 2015 it accelerated to 400ppm.If global energy demand continues to grow, the $\mathrm{CO}_{2}$ emission is projected to exceed 900ppm by this century(2100).

\section{METHODOLOGY AND SOURCE OF DATA}

Semi-log regression model is applied to find linear trend which is given by,

$\log \left(\mathrm{x}_{\mathrm{i}}\right)=\mathrm{a}+\mathrm{bt}+\mathrm{u}_{\mathrm{i}}$

Where $\mathrm{x}_{\mathrm{i}}=$ variable to be estimated, $\mathrm{a}$ and $\mathrm{b}$ are constant, $\mathrm{t}$ $=$ time,$u_{i}=$ random error and $i=1,2, \ldots \ldots . . n$.

Then Cochrane and Orcutt(1949) model was applied to find the projection of global $\mathrm{CO}_{2}$ emission for 2030.

Hamilton (2018) regression filter model has been calculated in the following manner to find the decomposition of cyclical trends, cycles and seasonal variations.

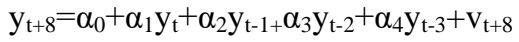

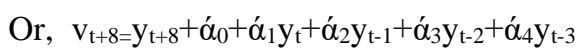

So, $\mathrm{y}_{\mathrm{t}}=\alpha_{0}+\alpha_{1} \mathrm{y}_{\mathrm{t}-8}+\alpha_{2} \mathrm{y}_{\mathrm{t}-9+} \alpha_{3} \mathrm{y}_{\mathrm{t}-10}+\alpha_{4} \mathrm{y}_{\mathrm{t}-11}+\mathrm{v}_{\mathrm{t}}$

Therefore, $\mathrm{v}_{\mathrm{t}}=\mathrm{y}_{\mathrm{t}}-\left(\dot{\alpha}_{0}+\dot{\alpha}_{1} \mathrm{y}_{\mathrm{t}-8}+\dot{\alpha}_{2} \mathrm{y}_{\mathrm{t}-9}+\dot{\alpha}_{3} \mathrm{y}_{\mathrm{t}-10}+\dot{\alpha}_{4} \mathrm{y}_{\mathrm{t}-11}\right)$ where $\dot{\alpha}_{\mathrm{i}}$ are estimated and $\mathrm{y}$ is the variable to be estimated.

$\mathrm{v}_{\mathrm{t}+\mathrm{h}}=\mathrm{y}_{\mathrm{t}+\mathrm{h}}-\mathrm{y}_{\mathrm{t}}$ is the difference i.e. how the series changes over $\mathrm{h}$ periods. For $\mathrm{h}=8$, the filter $1-\mathrm{L}^{\mathrm{h}}$ wipes out any cycle with frequencies exactly one year and thus taking out both long run trend as well as any strictly seasonal components.

It also applies random walk: $\mathrm{y}_{\mathrm{t}}=\mathrm{y}_{\mathrm{t}-1}-\varepsilon_{\mathrm{t}}$ where $\mathrm{d}=1$ and $\omega_{\mathrm{t}}^{\mathrm{h}}=\varepsilon_{\mathrm{t}+\mathrm{h}}+\varepsilon_{\mathrm{t}+\mathrm{h}-1}+\ldots \ldots \ldots \ldots+\varepsilon_{\mathrm{t}+1}$

Regression filter reduces to a difference filter when applied to a random walk. Hamilton suggested $h=8$ for business cycles and $\mathrm{h}=20$ for studies in financial cycles. Regression $\mathrm{v}_{\mathrm{t}}$ converges in large samples to $\alpha_{1}=1$ and all other $\alpha_{\mathrm{j}}$ $=0$.Thus, the forecast error is $\mathrm{v}_{\mathrm{t}+\mathrm{h}}=\mathrm{y}_{\mathrm{t}+\mathrm{h}}-\mathrm{y}_{\mathrm{t}}$.

The equation $\mathrm{v}_{\mathrm{t}}$ can be decomposed into trend, cycle and seasonally adjusted through SEATS/TRAMO or STL or census X-13 packages. The Box and Jenkins(1976) model The forecasting of $\operatorname{ARIMA}(p, d, q)$ has been applied in the Hamilton regression filter model for prediction in 2030. 
of $\operatorname{ARIMA}(\mathrm{p}, \mathrm{d}, \mathrm{q})$ can be estimated as below.

$\mathrm{v}_{\mathrm{t}}=\alpha+\beta_{0 \mathrm{i}} \mathrm{v}_{\mathrm{t}-\mathrm{i}}+\varepsilon_{\mathrm{t}}+\beta_{\mathrm{i}} \varepsilon_{\mathrm{t}-\mathrm{i}}+\grave{\mathrm{e}}_{\mathrm{t}}$

where $\mathrm{v}_{\mathrm{t}}=$ Hamilton regression filter residual, $\alpha$ is constant, $\beta_{0 \mathrm{i}}$ and $\beta_{\mathrm{i}}$ are the coefficients of AR and MA. AR terms and MA terms are $\mathrm{V}_{\mathrm{t}-\mathrm{i}}$ and $\varepsilon_{\mathrm{t}-\mathrm{i}}$ respectively where $\mathrm{i}=1,2 \ldots \ldots \ldots . \mathrm{n}$ , andè $=$ random error/residuals. For convergence criteria, $\beta_{0 \mathrm{i}}$ and $\beta_{\mathrm{i}}$ should be less than one and the values of AR and MA roots must be less than one for stability and stationary condition.

Data of global $\mathrm{CO}_{2}$ emission in Giga Ton from 1970 to 2018 were collected from the World Bank.

\section{OBSERVATIONS FROM THE MODELS}

Global $\mathrm{CO}_{2}$ emission has been catapulting at the rate of $1.74 \%$ per annum significantly during 1970-2018 which is estimated by the trend line given below.

$\log \left(\mathrm{x}_{1}\right)=2.741+0.0174 \mathrm{t}+\mathrm{u}_{\mathrm{i}}$

$$
(43.94) *(9.90) *
$$

$\mathrm{R}^{2}=0.99, \mathrm{DW}=1.31, \mathrm{AIC}=-235.31, \mathrm{SC}=-231.56, \mathrm{x}_{1}=$ global

$\mathrm{CO}_{2}$ emission in giga ton, ${ }^{*}=$ significant at $5 \%$ level., $\mathrm{u}_{\mathrm{i}}=$ residual.

In 2018,the global $\mathrm{CO}_{2}$ emission was 36.10gigaton which is projected to rise 63.503 Gigaton in 2050 which is depicted in Figure 1 below.

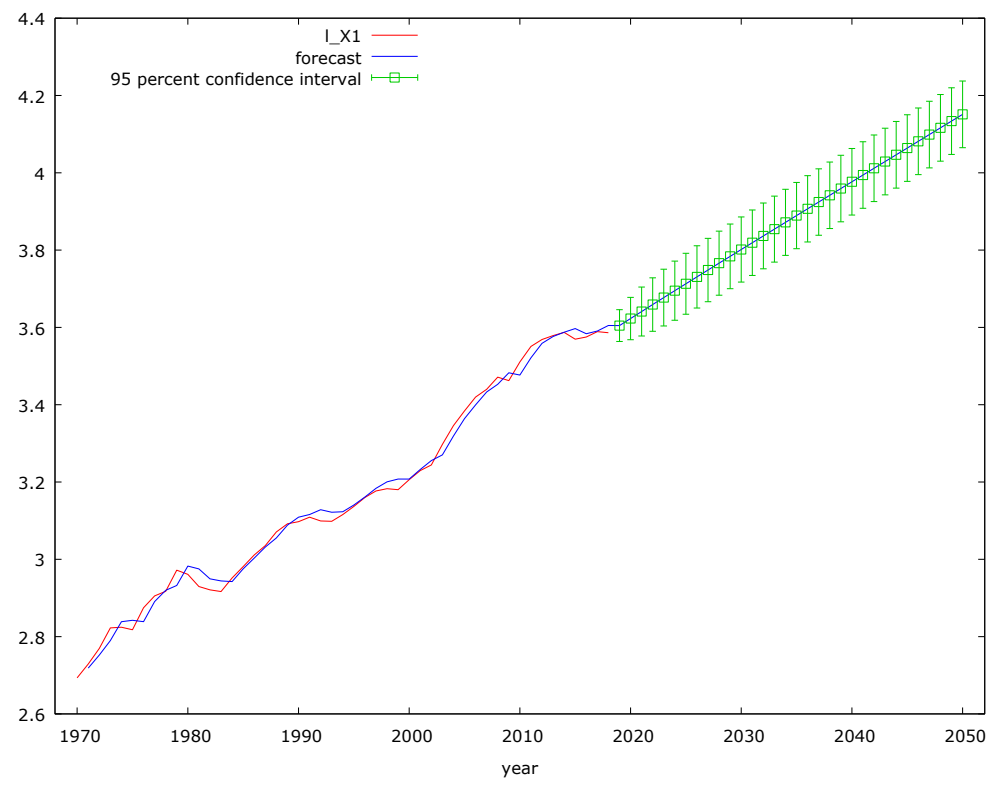

Fig.1: Global $\mathrm{CO}_{2}$ emission projection

Source: Plotted by author

Actually, the global $\mathrm{CO}_{2}$ emission fulfils the quadratic function properties which indicated that the trend line is non-linear and the estimated equation is given below.

$\log \left(\mathrm{x}_{1}\right)=2.748+0.013 \mathrm{t}+0.000105 \mathrm{t}^{2}+\mathrm{u}_{\mathrm{i}}$

$$
(159.11)^{*}(8.31)^{*}(3.41)^{*}
$$

$\mathrm{R}^{2}=0.98, \mathrm{~F}=1129.95^{*}, \mathrm{DW}=0.314,{ }^{*}=$ significant $\quad$ at $5 \%$ level, $\mathrm{u}_{\mathrm{i}}=$ residual.
This non-linear trend is significant at 5\% level having autocorrelation problem.

The global $\mathrm{CO}_{2}$ emission has the property of having five structural breaks in its path from 1970 to 2018 in $1977,1987,1996,2003$ and 2010 all of which are significant at 5\% level and all showed upward rising. It is depicted in Figure 2 below. 


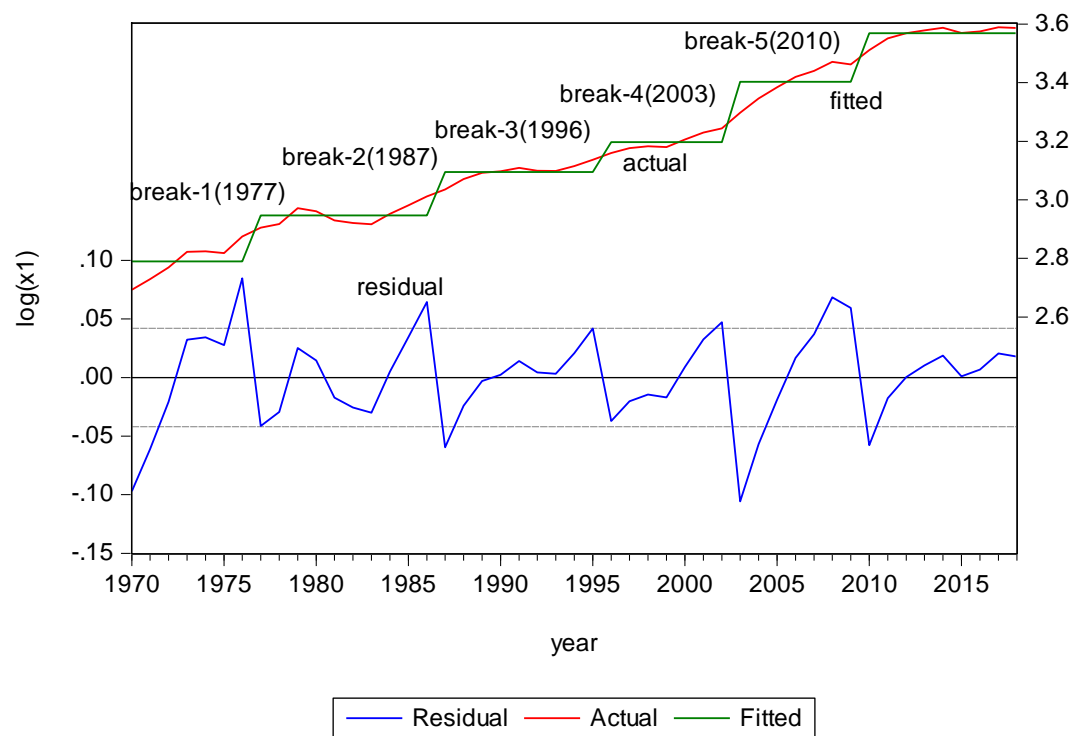

Fig.2: Structural breaks of global $\mathrm{CO}_{2}$ emission

Source: Plotted by author

Hamilton regression filter model of global $\mathrm{CO}_{2}$ emission during 1970-2018 is estimated below where the adjusted sample has fallen during 1981-2018 where total observations are 38 after adjustment.

$\log \left(\mathrm{x}_{1}\right)_{\mathrm{t}}=-0.2489+0.6954 \log \left(\mathrm{x}_{1}\right)_{\mathrm{t}-8}+0.2872 \log \left(\mathrm{x}_{1}\right)_{\mathrm{t}-9}$

$$
(-1.59) \quad(1.50) \quad(0.38)
$$

$-0.5741 \log \left(\mathrm{x}_{1}\right)_{\mathrm{t}-10}+0.7263 \log \left(\mathrm{x}_{1}\right)_{\mathrm{t}-11}+\mathrm{V}_{\mathrm{t}}$

$$
\mathrm{R}^{2}=0.94, \mathrm{~F}=129.50 *, \mathrm{DW}=0.283, \mathrm{AIC}=-2.71, \mathrm{SC}=-2.49
$$

The Hamilton regression filter is found as a good fit with high $\mathrm{R}^{2}$ and significant $\mathrm{F}$ values with low $\mathrm{AIC}$ and $\mathrm{SC}$ respectively and all the coefficients are less than one.The residual $\mathrm{v}_{\mathrm{t}}$ is calculated as

$\mathrm{v}_{\mathrm{t}}=\log \left(\mathrm{x}_{1}\right) \quad-\left[-0.2489+0.6954 \log \left(\mathrm{x}_{1}\right)_{\mathrm{t}-8}+0.2872 \log \left(\mathrm{x}_{1}\right)_{\mathrm{t}-9^{-}}\right.$ $\left.0.5741 \log \left(\mathrm{x}_{1}\right)_{\mathrm{t}-10}+0.7263 \log \left(\mathrm{x}_{1}\right)_{\mathrm{t}-11}\right]$

This equation can be treated as Hamilton filter model of global $\mathrm{CO}_{2}$ emission.

The estimated Hamilton regression filter equation is plotted in Figure 3 where fitted and actual lines are shown as upward rising and the residual consists of 7 peaks and troughs respectively whose cyclical trend is diverging away from equilibrium with rising volatility.

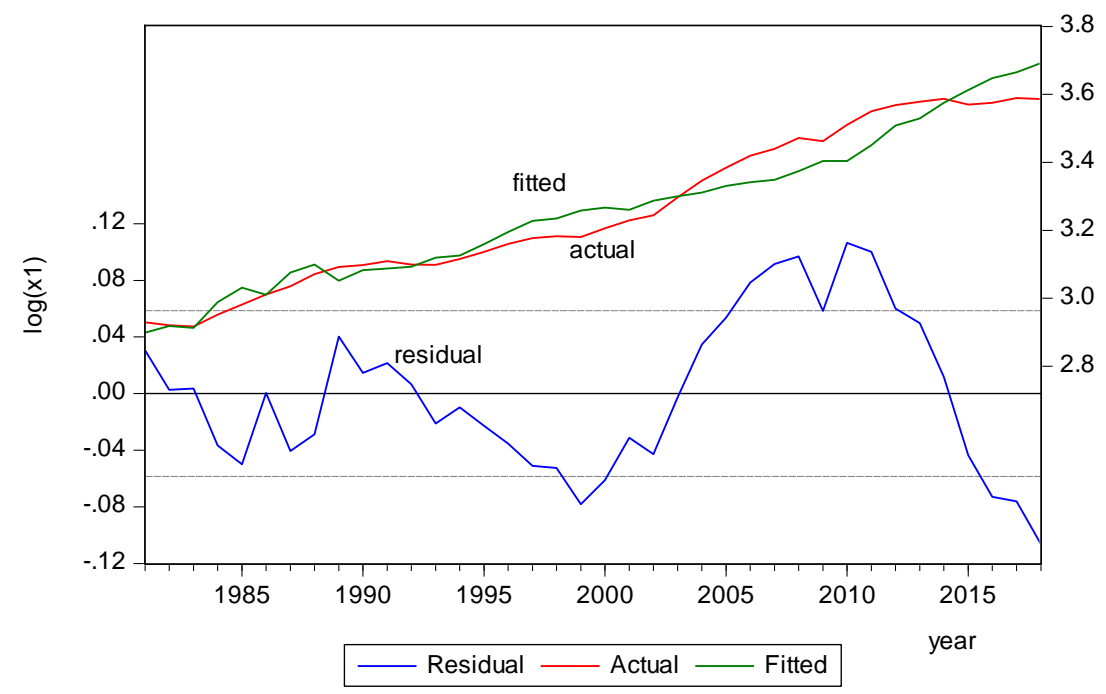

Fig.3: Hamilton regression filter

Source-Plotted by author 
Hamilton filter residual of global $\mathrm{CO}_{2}$ emission during 1970-2018 has been decomposed into trend, cycle, seasonal variation, remainder, seasonally adjusted cycle respectively in a panel of diagrams in Figure 4 below. In panel1, the Hamilton filter residual is shown as a cyclical pattern having seven peaks and troughs. In panel 2,the smooth cyclical trend is plotted which minimises cycles showing two peaks and troughs where amplitude is widening. In panel 3,the seasonal variation is shown where its patterns are $\mathrm{v}$ shaped. In panel 4, the remainder is presented which is fluctuating and in panel 5,the seasonally adjusted cycle is visible which looks as like as residual line. Resid01
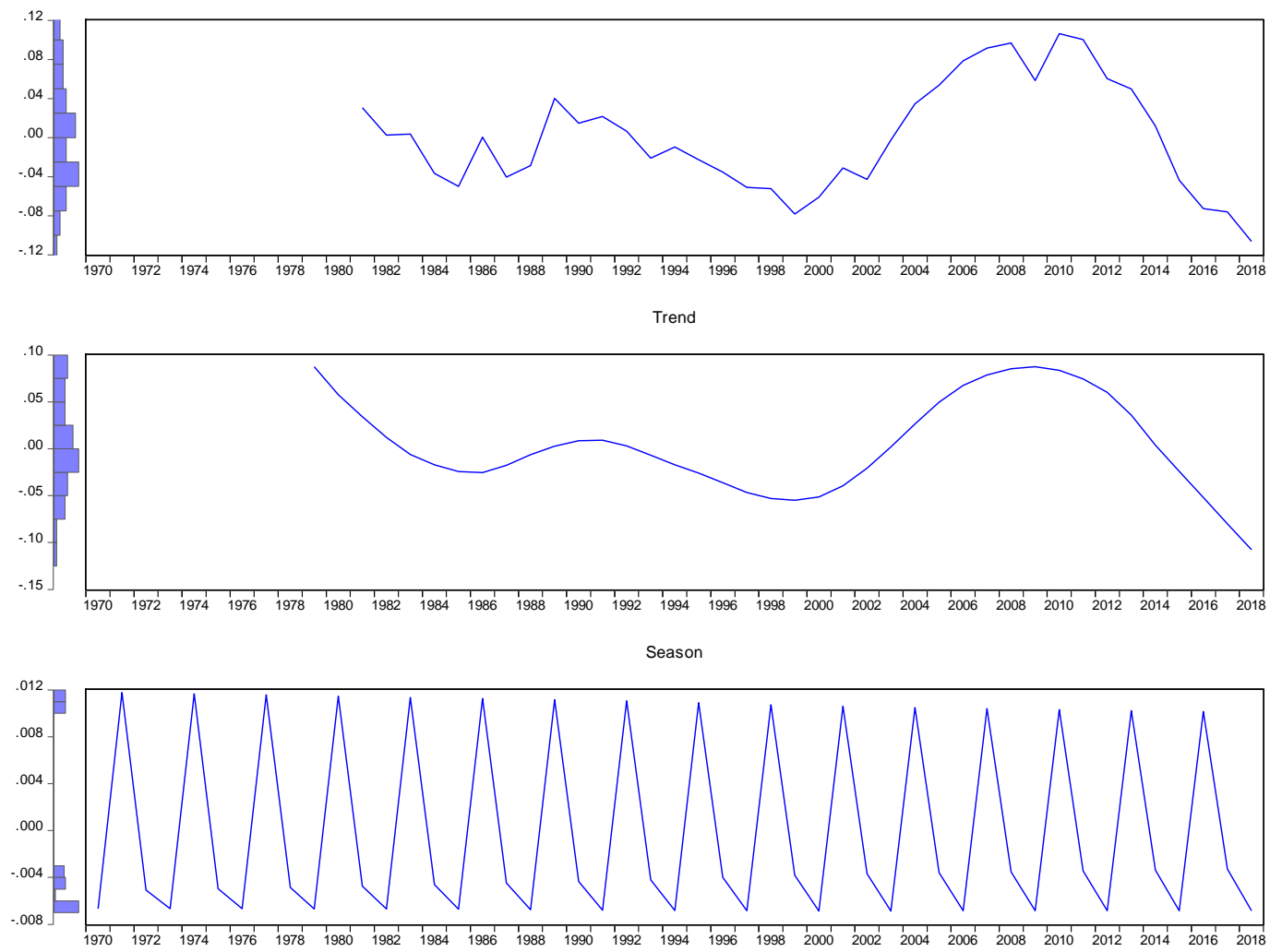

Remainder

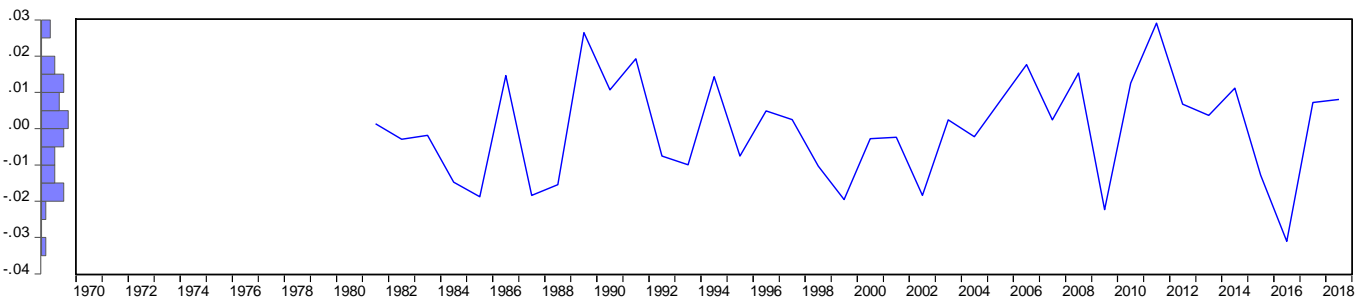

Adjusted

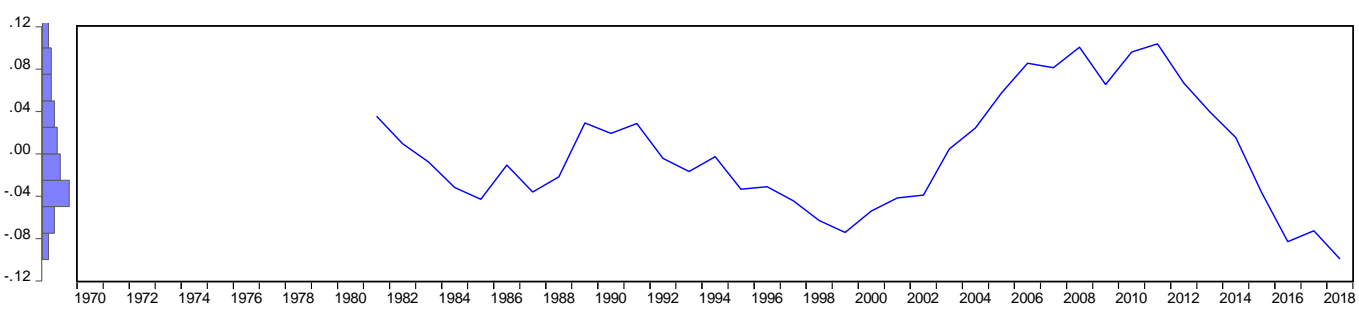

Fig.4: Decomposition of Hamilton regression filter of global $\mathrm{CO}_{2}$

Source-Plotted by author

In the Figure 5, the Hamilton filter of global $\mathrm{CO}_{2}$ emission, its cycle, trend and seasonal adjustment is plotted in the composite figure. The Hamilton filter trend line exemplified with two peaks and troughs which are diverging with bigger 
amplitude. There is no wide difference between seasonally adjusted and the actual residual of the filter of global $\mathrm{CO}_{2}$, although both of which are cyclical with upswings and downswing phases.

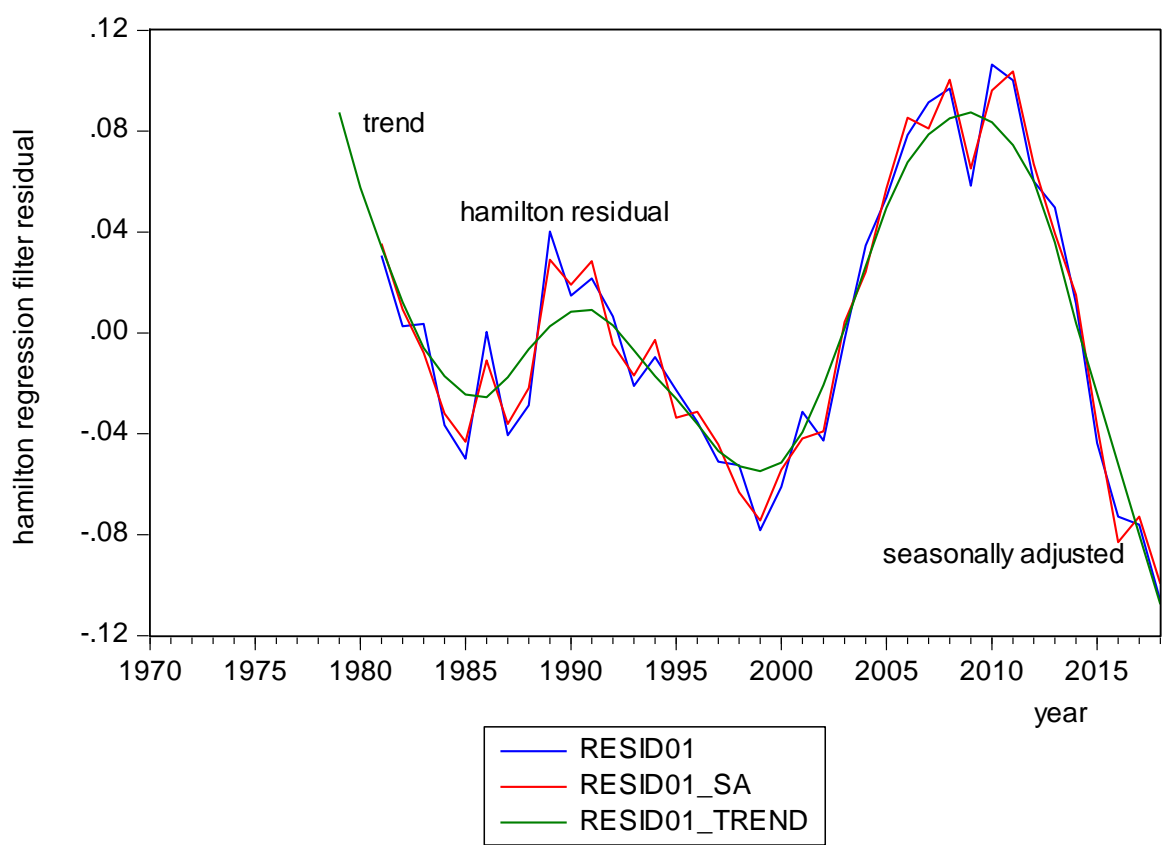

Fig.5: Cycle, trend and seasonal adjustment

Source-Plotted by author

The seasonal fluctuation can be confirmed by the application of finding auto correlation functions and partial autocorrelation functions of the Hamilton regression filter residual series of the global $\mathrm{CO}_{2}$ emission from 1970 to 2018.The ACF have been declining up to lag 4 and then it reached negative which are increasing up to lag 11 and started to diminish up to lag 14 and then it moved up towards positive values from lag 15.Similarly PACF declined up to lag 2 and then turned to negative up to lag 4 and from lag 6 the negative values increased up to lag 10 and reached positive values up to lag 13 and then fell negative. The patterns of ACF and PACF indicate that the seasonal fluctuation of global $\mathrm{CO}_{2}$ emission is confirmed since the probabilities of $\mathrm{Q}$ stat are significant. In Figure 6,it proves clearly.

\begin{tabular}{|c|c|c|c|c|c|c|c|c|}
\hline \multicolumn{2}{|c|}{ Autocorrelation } & \multicolumn{2}{|c|}{ Partial Correlation } & & $A C$ & PAC & Q-Stat & Prob* \\
\hline 1 & & 1 & & 1 & 0.688 & 0.688 & 19.435 & 0.000 \\
\hline 1 & & 1 & 1 & 2 & 0.483 & 0.018 & 29.271 & 0.000 \\
\hline & $\square$ & । & । & 3 & 0.337 & -0.002 & 34.211 & 0.000 \\
\hline & 1 & $\square$ & । & 4 & 0.037 & -0.378 & 34.271 & 0.000 \\
\hline & 1 & । & । & 5 & -0.095 & 0.020 & 34.686 & 0.000 \\
\hline $1 \square$ & 1 & 1 & 1 & 6 & -0.175 & -0.047 & 36.148 & 0.000 \\
\hline IL & 1 & 1 니 & । & 7 & -0.292 & -0.094 & 40.328 & 0.000 \\
\hline ᄃ & । & 니 & । & 8 & -0.304 & -0.069 & 45.015 & 0.000 \\
\hline ᄃ & 1 & 1 & । & 9 & -0.306 & -0.075 & 49.917 & 0.000 \\
\hline & । & । 뭉 & । & 10 & -0.373 & -0.200 & 57.465 & 0.000 \\
\hline & 1 & 1 다 & । & 11 & -0.378 & -0.136 & 65.516 & 0.000 \\
\hline & 1 & & । & 12 & -0.284 & 0.088 & 70.219 & 0.000 \\
\hline $1 \square$ & 1 & I & 1 & 13 & -0.173 & 0.112 & 72.047 & 0.000 \\
\hline 1 & 1 & 1 & 1 & 14 & -0.059 & -0.015 & 72.268 & 0.000 \\
\hline 1 & । & 1 & 1 & 15 & 0.066 & -0.036 & 72.552 & 0.000 \\
\hline 1 & 1 & $1 \square$ & 1 & 16 & 0.076 & -0.182 & 72.954 & 0.000 \\
\hline
\end{tabular}

Fig.6: AC and PAC of Hamilton filter residual

Source-Plotted and calculated by author

Among the best 20 models of automatic forecasting of Autoregressive Integrated Moving Average of Hamilton

regression filter models of global $\mathrm{CO}_{2}$ emission,the $\operatorname{ARIMA}(4,0,0)$ model is selected for forecasting for 
2030.By applying ARMA maximum likelihood method after adjusting sample during 1981-2018,the estimated equation is observed as below.

$\mathrm{v}_{\mathrm{t}}=0.00221+0.8635 \mathrm{v}_{\mathrm{t}-1}+0.0452 \mathrm{v}_{\mathrm{t}-2}+0.4387 \mathrm{v}_{\mathrm{t}-3}$

$$
(0.127) \quad(4.98)^{*} \quad(0.18) \quad(2.17)^{*}
$$

$-0.6406 \mathrm{v}_{\mathrm{t}-4}+0.000453 \sigma_{\mathrm{t}}^{2}$

$$
(-4.85)^{*} \quad(4.11)^{*}
$$

$\mathrm{R}^{2}=0.84, \mathrm{~F}=35.65^{*}, \mathrm{DW}=2.084, \mathrm{AIC}=-4.44, \mathrm{SC}=-4.18, \mathrm{AR}$ roots $=0.89 \pm 0.32 \mathrm{i}, \mathrm{MA}$ roots $=-0.46 \pm 0.70 \mathrm{i}$

The ARIMA $(4,0,0)$ forecasting model of Hamilton residual is highly significant showing minimum volatility where the coefficient of $\sigma^{2}$ is minimum and significant along with other three coefficients.Even, $\mathrm{R}^{2}$ is high, $\mathrm{F}$ is significant, $\mathrm{AIC}$ is minimum and the roots of AR and MA are less than one which revealed that the both $\mathrm{AR}$ and MA processes are convergent,stable and stationary.

In Figure 7,the forecast $\operatorname{ARIMA}(4,0,0)$ is depicted neatly where the forecast value for 2030 is (0.044088) in comparison with the value of (-0.0950) at 2018 and forecast line is moving upward up to 2027 and then it is declining although its amplitudes were increasing up till 2010.

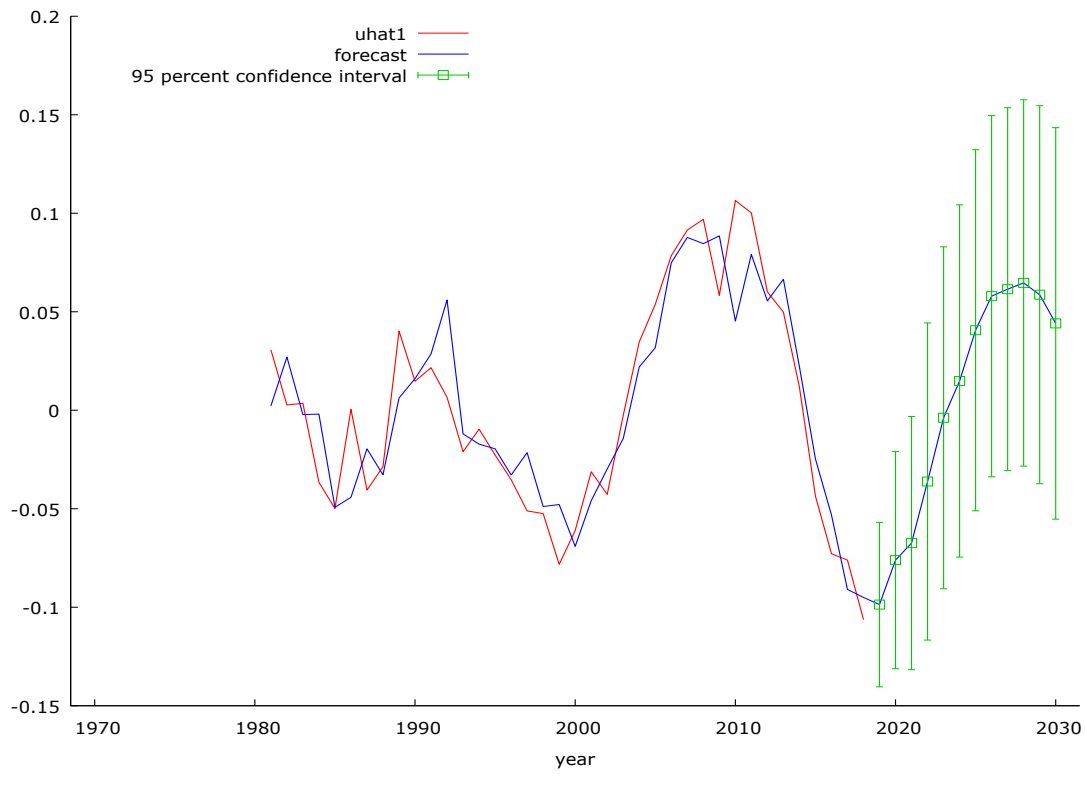

Fig.7: ARIMA forecast in Hamilton filter model

Source- Plotted by author

The heteroscedasticity test for residual of $\operatorname{ARIMA}(4,0,0)$ by applying $\mathrm{ARCH}(4)$ revealed that $\mathrm{nR}^{2}=3.0166$ because $\mathrm{n}=34, \mathrm{R}^{2}=0.088872$ which is accepted by Chi-square(4) test whose probability is found as 0.55 ( where $\mathrm{F}=0.7058$ whose probability is 0.59) after adjusting the sample during 19852018 which implied that no heteroscedasticity is accepted at null hypothesis.

\section{LIMITATIONS AND SCOPE FOR FUTURE STUDIES}

The paper did not compare the observations of decompositions of Hamilton regression filter model with the Hodrick-Prescott Filter model.If the quarterly or monthly data of $\mathrm{Co}_{2}$ emission were taken then the observations from Hamilton filter will be more perfect and analytic. The details of autocorrelation and partial autocorrelation functions are not shown step by step of all lags.Application of Hamilton filter through ARIMA(p,d,q) forecast model may produce many debates. The clarifications of explaining amplitudes were not included in this analysis.Even,the explanation of volatility through appropriate GARCH model is also absent here.Therefore,there is enough scope of future research in the context of this paper.

\section{MODEL DEMANDS POLICIES}

Based on Business as Usual trend,global $\mathrm{CO}_{2}$ emission is projected to increase some 43.08 billion metric ton in 2050 in comparison to 35.3 billion metric ton in 2018.By $2100, \mathrm{CO}_{2}$ concentration will reach between $540-970 \mathrm{ppm}$ as compared to $368 \mathrm{ppm}$ in 2000.(https://www.aceracre.ca/resources/climate-change-in-context/introduction- 
2/global/scientific-projections/projections-for-carbondioxide).By 2100,cumulative global $\mathrm{CO}_{2}$ emission will exceed 1 trillion tons of carbons (3.67 trillion of $\mathrm{CO}_{2}$ ) threshold which according to IPCC will raise the earth's surface temperature to $2^{\circ} \mathrm{C}$ above the pre-industrial minimum and trigger dangerous interference. (http://euanmearns.com/global-co2-emissions-forecast-to2100/).

Paris Climate Agreement targets to limit temperature rise with in $1.5^{\circ} \mathrm{C}$ that might increase global GDP by $60-65 \%$ by 2030.The agreement claims to reduce $\mathrm{CO}_{2}$ emission by $20 \%$ along with $20 \%$ increase in renewable energy and energy efficiency respectively. As a whole, GHG emissions intensity must be reduced by 33-35\% below 2005 level within 2030. So, to limit global temperature rise to $1.5^{\circ} \mathrm{C}$,emissions must be below 25gigatons by 2030.As on 2020,February, 194 states with EU agreed the Paris Agreement where 188 countries plus EU represent more than $87 \%$ of GHGs. China had committed to cut GHGs by 26-28\% by 2025 and USA assured to cut through Clear Power Plan. India is also committed to reduce the emissions intensity of its GDP by 33 to 35 percent by 2030 from 2005 levels. India's emission intensity has reduced by $21 \%$ over the period 2005-2014. By 2030, India's emission intensity is projected to be even lower-in the range of 35 to 50 percent. (https://www.nrdc.org/experts/anjali-jaiswal/roadparis-indias-advancement-its-climate-pled).

\section{CONCLUSIONS}

The paper concludes that the global $\mathrm{CO}_{2}$ emission has been catapulting at the rate of $1.74 \%$ per annum significantly during 1970-2018 and its projected value of 2050 is 63.503gigaton in comparison to 36.10 gigaton in 2018. Hamilton regression filter showed that global $\mathrm{CO}_{2}$ is cyclical in patterns having 7 peaks and troughs but the smooth cyclical trend consists of two distinct peaks and troughs which are widening in the amplitude and the seasonal variation is $\mathrm{v}$ shaped when it is decomposed by STL method. The seasonal variation is confirmed by the patterns of ACF and PACF whose Q stat are significant at $5 \%$ level. Automatic forecasting $\operatorname{ARIMA}(4,0,0)$ model for 2030 is incorporated with Hamilton filter and the result is appeared as convergent, stable and stationary with minimum volatility. This model is free from heteroscedasticity problem.

\section{ACKNOWLEDGEMENT}

I do hereby acknowledge that there is no source of finance for funding to prepare this paper and there is no co-author. All the sources of literature and data are secondary. I am responsible for all errors and omissions.

\section{REFERENCES}

[1] Baxter, M., \& King, R. G. (1999). Measuring business cycles: Approximate band-pass filters for economic Time Series. Review of Economics and Statistics,81(4),575-593. https://EconPapers.repec.org/RePEc:tpr:restat:v:81:y:1999:i :4:p:575-593.

[2] Bhowmik,Debesh.(2018). Linkage between global CO2 emission and world GDP.In Doifode,Shamal.K \& Matani,Ashoke G.(Eds.),Renewable Energy Sources \& Environment Protection(pp 93-120),Delhi:International Research Publication House.

[3] Bhowmik,Debesh.(2020). Cyclical and seasonal patterns of India's GDP growth rate through the eyes of Hamilton and Hodrick-Prescott Filter models.(In Press).

[4] Box, George.,\& Jenkins,Gwilym.(1976).Time Series Analysis, Forecasting,and Control. San Francisco: Holden Day.Retrieved from

http://garfield.library.upenn.edu/classics1989/A1989AV48500 001.pdf.

[5]Christiano, L.J., \& Fitzgerald, T. J. (2003). The band pass filter. International Economic Review,44(2),435-465.

https://EconPapers.repec.org/RePEc:ier:iecrev:v:44:y:2003:i:2: $\mathrm{p}: 435-465$

[6]Ciais, Philippe et al.(2018).Carbon and other Biogeochemical Cycles. In Chapter 06 of WG1ARS of IPCC (pp.465-570).

https://www.ipcc.ch/site/assets/uploads/2018/02/WG1AR5_Ch apter06_FINAL.pdf

[7]Cochrane,D.,\& Orcutt,G.H.(1949).Application of Least Squares Regression to Relationships Containing AutoCorrelated Error Terms.Journal of the American Statistical Association,44(245),32-61.Retrieved from https://doi.org/10.1080/01621459.1949.10483290

[8]EDGAR.(2020).Trends in Global CO2 emissions:2016Report.Retrieved from https://edgar.jrc.ec.europa.eu/news_docs/jrc-2016-trends-inglobal-co2-emissions-2016-report-103425.pdf

[9]Hamilton, J. D. (2018). Why you should never use the Hodrick-Prescott Filter. Review of Economics and Statistics,100(5),831-843. Retrieved from https://econweb.ucsd.edu/ jhamilto/hp.pdf.

[10]Hodrick, R.J., \& Prescott, E.C.(1997,February).Post-war US Business Cycles :An Empirical Investigation. Journal of Money, Credit and Banking,29(1),1-16.Retrieved from https://www0.gsb.columbia.edu/faculty/rhodrick/prescotthodrick1997.pdf.

[11]Hodrick,R.J.(2020,February).An explanation of trend-cycle decomposition methodologies in simulated data. (NBER Working Paper 26750).Retrieved from http:www.nber.org/paper/w26750.pdf 
[12]Lindsey, Rebecca. (2020, August 14). Climate Change: Atmospheric Carbon Dioxide. Retrieved from https://www.climate.gov/news-features/understandingclimate/climate-change-atmospheric-carbon-dioxide.

[13]Oliver,J.G.J.,\&Peter,J.A.H.W.(2020,May).Trends in

Global CO2 and Total Green House Gas Emission:2019

Report.PBL Netherland Environmental Assessment Agency. Retrieved from

https://www.pbl.nl/sites/default/files/downloads/pbl-2020trends-in-global-co2-and-total-greenhouse-gas-emissions2019-report_4068.pdf

[14]Schuler, Y.S. (2018).On the Cyclical properties of Hamilton's regression filter. Discussion Paper-03,Deutsche Bundesbank.Retrieved

from https://ideas.repec.org/p/zbw/bubdps/032018.html 